\title{
Cardiac surgery in acute myocardial infarction: crystalloid versus blood cardioplegia - an experimental study
}

\author{
Andreas Boening ${ }^{1}$, Maximilian Hinke ${ }^{1}$, Martina Heep ${ }^{1}$, Kerstin Boengler², Bernd Niemann ${ }^{1}$ and \\ Philippe Grieshaber ${ }^{1 *}$ (D)
}

\begin{abstract}
Background: Because hearts in acute myocardial infarction are often prone to ischemia-reperfusion damage during cardiac surgery, we investigated the influence of intracellular crystalloid cardioplegia solution (CCP) and extracellular blood cardioplegia solution (BCP) on cardiac function, metabolism, and infarct size in a rat heart model of myocardial infarction.

Methods: Following euthanasia, the hearts of 50 rats were quickly excised, cannulated, and inserted into a blood-perfused isolated heart apparatus. A regional myocardial infarction was created in the infarction group (18 hearts) for 120 min; the control group (32 hearts) was not subjected to infarction. In each group, either Buckberg BCP or Bretschneider CCP was administered for an aortic clamping time of $90 \mathrm{~min}$. Functional parameters were recorded during reperfusion: coronary blood flow, left ventricular developed pressure (LVDP) and contractility (dp/dt max). Infarct size was determined by planimetry. The results were compared between the groups using analysis of variance or parametric tests, as appropriate.

Results: Cardiac function after acute myocardial infarction, $90 \mathrm{~min}$ of cardioplegic arrest, and $90 \mathrm{~min}$ of reperfusion was better preserved with Buckberg BCP than with Bretschneider CCP relative to baseline (BL) values (LVDP $54 \pm 11 \%$ vs. $9 \pm$ $2.9 \%[p=0.0062] ; \mathrm{dp} / \mathrm{dt}$ max. $73 \pm 11 \%$ vs. $23 \pm 2.7 \%$ [ $p=0.0001]$ ), whereas coronary flow was similarly impaired (BCP $55 \pm$ $15 \%$, CCP $63 \pm 17 \%$ [ $p=0.99]$ ). The infarct in BCP-treated hearts was smaller (25\% of myocardium) and limited to the area of coronary artery ligation, whereas in CCP hearts the infarct was larger ( $48 \%$ of myocardium; $p=0.029$ ) and myocardial necrosis was distributed unevenly to the left ventricular wall.
\end{abstract}

Conclusions: In a rat model of acute myocardial infarction followed by cardioplegic arrest, application of BCP leads to better myocardial recovery than CCP.

Keywords: Blood cardioplegia, Crystalloid cardioplegia, Myocardial revascularization, Myocardial infarction, Ischemiareperfusion injury

\section{Background}

Acute myocardial infarction can be treated by either percutaneous coronary intervention or coronary artery bypass grafting surgery (CABG) [1]. In this setting, the optimal timing of CABG has been a matter of debate for decades. More recent data suggest that immediate surgery is equally

\footnotetext{
* Correspondence: philippe.grieshaber@chiru.med.uni-giessen.de The results of this investigation were presented at the $48^{\text {th }}$ meeting of German Society for Thoracic, Vascular, and Cardiac Surgery (Wiesbaden, February 2019)

'Department of Cardiovascular Surgery, University Hospital Giessen, Rudolf-Buchheim-Str. 7, 35392 Giessen, Germany

Full list of author information is available at the end of the article
}

safe and possibly associated with improved outcomes compared to delaying surgery for some days after the acute event $[2,3]$. If immediate CABG is the method chosen for myocardial revascularization, the procedure is usually carried out using a heart-lung machine [4]. During cardiac procedures, the goal of myocardial protection is to maximize the functional recovery after cardioplegic cardiac arrest and to minimize the extent of ischemia-reperfusion injury. Adequate myocardial protection of infarcted hearts is challenging compared to the setting of non-infarcted hearts due to pre-existing ischemic damage of the cardiomyocytes, intracellular ATP (adenosine tri phosphate)

(C) The Author(s). 2020 Open Access This article is distributed under the terms of the Creative Commons Attribution 4.0 International License (http://creativecommons.org/licenses/by/4.0/), which permits unrestricted use, distribution, and 
depletion, decrease of cellular $\mathrm{pH}$ and changes of the electrolyte distribution $[5,6]$. Generally, different cardioplegia solutions are available for inducing cardiac arrest: crystalloid (CCP) or blood-based (BCP) solutions. Bretschneider CCP is an sodium-poor intracellular cardioplegic solution acting through depletion of extracellular sodium. It is usually applied as a single infusion. Contrarily, Buckberg's BCB is a potassium-rich extracellular cardioplegic solution acting through stabilization of the cell membrane potential between -35 and $-60 \mathrm{mV}$. It is usually applied as repeated infusions [7]. Both solutions have been tested experimentally and clinically, but the results even of meta-analyses are conflicting: Zeng et al. 2014 [8] and Guru et al. 2006 [9] showed superiority of BCP (lower myocardial infarction rate, lower rate of low output syndrome, and lower enzyme release), Sa et al. 2012 [10] found no difference between $\mathrm{BCP}$ and $\mathrm{CCP}$ regarding risk of death, myocardial infarction, and low output syndrome. Likewise, experimental results have shown superiority of BCP [11-15] or of CCP [16]. Thus, although there are many reports comparing $\mathrm{CCP}$ and $\mathrm{BCP}$, it is still unclear which can better prevent ischemia-reperfusion damage.

The goal of this study was to compare the influence of CCP and BCP on cardiac function, metabolism, and infarct size in a rat heart model of myocardial infarction.

\section{Materials and methods}

\section{Experimental model}

This study investigated the effect of different two different cardioplegia solutions on isolated infarcted rat hearts in the experimental setting of a blood-perfused Langendorff apparatus. Control hearts underwent the same experimental procedure without induction of a myocardial infarction.

A Langendorff apparatus (Hugo Sachs, Hugstetten, Germany) was filled with freshly prepared, filtered, heparinized bovine erythrocyte concentrates and warmed to a temperature of $36^{\circ} \mathrm{C}$. Physiological conditions were maintained: the hemoglobin content of our perfusion solution was between 6.0 and $7.0 \mathrm{mg} / \mathrm{dl}$. End-diastolic pressure was adjusted to $10-12 \mathrm{mmHg}$ by adding or subtracting volume from the balloon during the first perfusion period of 30 min. After starting the experiment by clamping the aorta, the volume was kept constant. The model has already been described in more detail [17]. After excision of the hearts and during the reperfusion period on the Langendorff apparatus, a myocardial infarction was created in the infarction group by ligation of the left anterior descending coronary artery (LAD) for $120 \mathrm{~min}$. The hearts in the control group did not undergo ligation. After $30 \mathrm{~min}$. of local myocardial inschemia, the aorta was 'clamped' for $90 \mathrm{~min}$. Using a three-way-stopcock in the perfusion line. During the $90 \mathrm{~min}$. Clamping time, the hearts were protected with either Bretschneider CCP or Buckberg BCP. The LAD was removed before reperfusing the heart (Fig. 1). To mimic the clinical situation where myocardial protection with $\mathrm{BCP}$ and also with CCP is combined with warm $\left(36^{\circ} \mathrm{C}\right)$ extracorporeal circulation, the heart was suspended in a heated $\left(36^{\circ} \mathrm{C}\right)$ chamber. During $90 \mathrm{~min}$ of reperfusion, functional parameters were recorded, including coronary blood flow, left ventricular developed pressure (LVDP), and contractility (dp/dt max).

Isovolumetric measurement of left ventricular (LV) performance was carried out using a compliant latex balloon (maximal volume $0.1 \mathrm{ml}, 73-2813 \mathrm{IH}-\mathrm{SR}$ Balloon Kit for Rats and Guinea Pig Hearts, Hugo Sachs, Hugstetten, Germany) inserted in the LV across the mitral valve that was connected to a pressure transducer. The volume of the saline-filled balloon was kept constant during the entire experiment. LV performance was assessed by measurement of LV systolic pressure (LVSP) and LV end-diastolic pressure $(\mathrm{mmHg}$; LVSP - LV end-diastolic pressure $=$ LVDP). Positive and negative first derivatives of LVSP $(+\mathrm{dP} / \mathrm{dt}$ and $-\mathrm{dP} /$ $\mathrm{dt} ; \mathrm{mmHg} / \mathrm{s}$ ) were recorded by a transducer-amplifier module (TAM-A, Harvard Apparatus Hugstetten, Germany) and calculated by the software "Isoheart" (Harvard Apparatus). While aortic pressure was held at a constant 70 $\mathrm{mmHg}$ by a pressure controller, coronary flow $(\mathrm{ml} / \mathrm{min})$ was measured. The results were calculated as percent of baseline to correct for initial differences (Table 1). Baseline hemodynamic measurements were taken after the 30-min stabilization period and before ligature of the LAD or aortic clamping.

\section{Animals and groups}

Following euthanasia, the hearts of 50 (age: 3-4 months, weight: 225-350 g) male Wistar rats (Janvier, St. Berthevin, France) were quickly excised, cannulated, and inserted into the blood-perfused isolated heart apparatus. A total of 18 hearts underwent acute myocardial infarction, as described above. Thereof, 9 hearts were protected with cold Buckberg BCP and 9 with cold Bretschneider CCP. A total of 32 hearts served as control groups with 16 hearts in the cold Buckberg $\mathrm{BCP}$ group and 16 hearts in the cold Bretschneider CCP group, respectively. All experiments were approved by the regional authorities and conformed to the German Animal Protection Law.

\section{Cardioplegia}

Cold Buckberg BCP was administered in a 4:1 (blood:BCP) dilution. BCP was prepared using the bovine erythrocyte solution used for perfusion of the hearts and a commercially available solution (Köhler Chemie, Bensheim, Germany; [Table 2]). The BCP application flow rate was calculated as the amount of baseline coronary flow $+30 \%$ (in $\mathrm{ml} / \mathrm{min}$ ); At this flow rate, cold induction and hot shot were applied over $4 \mathrm{~min}$ each, the repeated doses every 20 min over 2 min each. After having measured coronary flow under baseline conditions (Fig. 1), we added a 30\% safety 


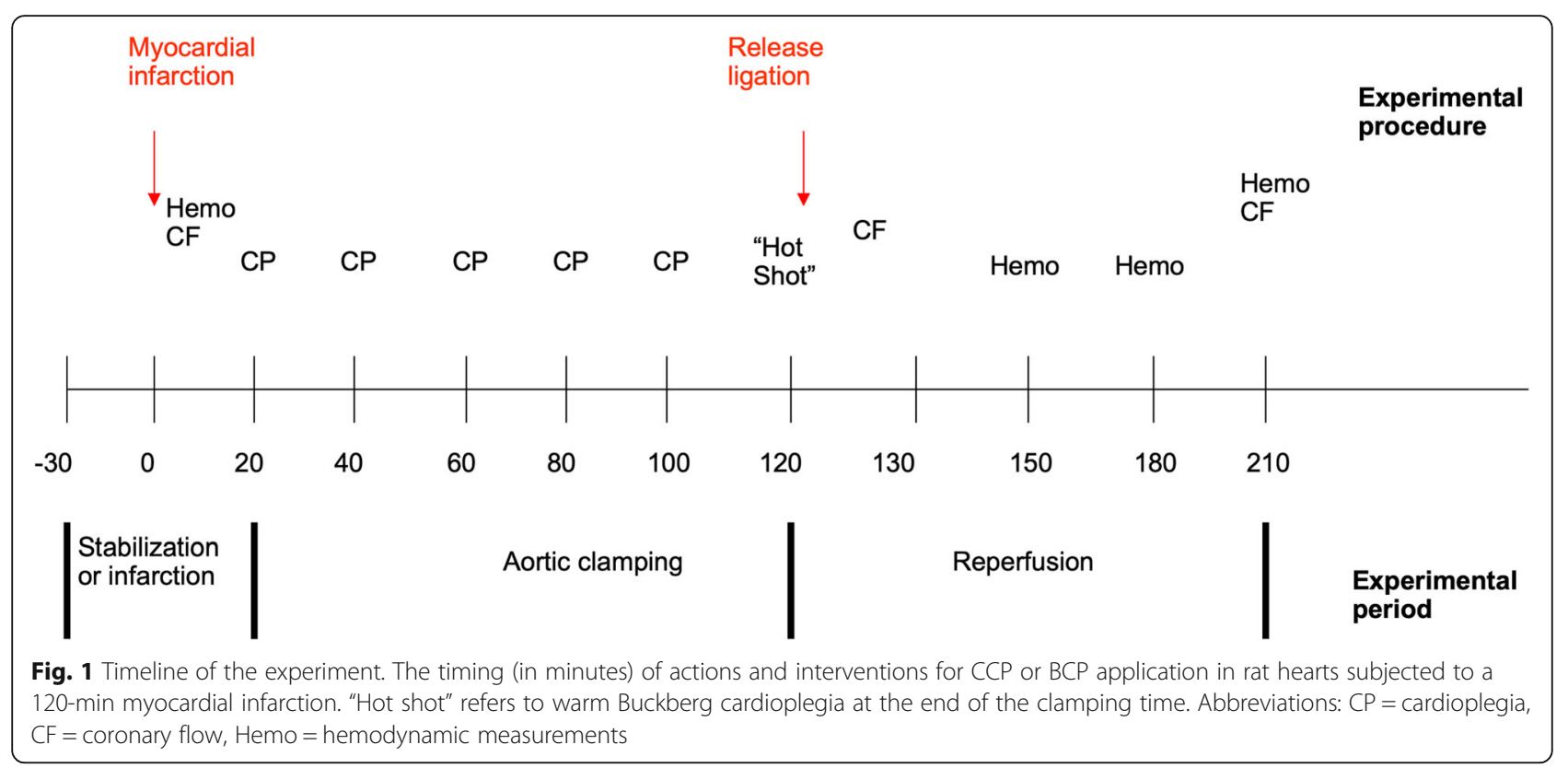

margin to the baseline flow to ensure that sufficient $\mathrm{BCP}$ was administered. The single dose of cold CCP consisted of $30 \mathrm{ml}$ Bretschneider CCP (Köhler Chemie, Bensheim, Germany) applied under $50-70 \mathrm{mmHg}$ aortic pressure (corresponding to the usually clinically used 120-140 mbar hydrostatic perfusion pressure). The amount of Bretschneider CCP was calculated according to the manufacturer's instruction for use assuming an estimated heart weight of $4 \mathrm{~g}$ $(1 \mathrm{ml} \mathrm{CCP}$ per minute and gram heart weight over $8 \mathrm{~min}$ resulting in $32 \mathrm{ml} \mathrm{CCP)}$.

\section{Infarct size planimetry}

After 90 min of reperfusion, the hearts of the infarction group were removed from the perfusion apparatus and frozen at $-20^{\circ} \mathrm{C}$ for $30 \mathrm{~min}$. Subsequently, hearts were cut into 7-8 slices and incubated in $1.2 \%$ triphenyl tetrazolium chloride for $20 \mathrm{~min}$ at $37^{\circ} \mathrm{C}$. Heart slices were then fixed in $7 \%$ formalin at room temperature overnight. Digital images were taken of both sides of the heart slices with a M60 microscope (Leica, Wetzlar, Germany) at 2.5-fold magnification. Infarct size was determined by planimetry using the Leica Application Suite LAS version 4.6 (Leica).

\section{Statistical analysis}

Hemodynamic parameters obtained at different time points after the end of cardioplegia or opening of the aortic clamp were expressed relative to baseline (BL) and analyzed using SPSS statistical software version 24 (IBM, Ehningen, Germany). Intergroup differences in hemodynamic parameters and results of cardiac metabolism (response variables) over time were analyzed using two-way ANOVA (analysis of variance) models with "time points" (categorical) as the within-subject factor and "group" (categorical: "CCP infarction" "BCP infarction", "CCP non-infarction", and "BCP noninfarction") as the between-subjects factor. Tukey's post-hoc test was used if any difference was observed. The infarct sizes were compared between the groups using a two-sided Student's t-test. Data are shown as mean \pm SD. Statistical significance was assumed at a level of $p<0.05$.

Table 1 Baseline values of hemodynamic parameters

\begin{tabular}{|c|c|c|c|c|c|}
\hline & $\begin{array}{l}\text { Buckberg Infarction } \\
(n=9)\end{array}$ & $\begin{array}{l}\text { Bretschneider } \\
\text { Infarction }(n=9)\end{array}$ & $\begin{array}{l}\text { Buckberg No } \\
\text { infarction }(n=16)\end{array}$ & $\begin{array}{l}\text { Bretschneide No } \\
\text { infarction }(n=16)\end{array}$ & $p$-Value ${ }^{*}$ \\
\hline Coronary flow (ml/min) & $4 \pm 0.3$ & $4 \pm 0.6$ & $3 \pm 0.3$ & $4 \pm 0.4$ & 0.99 \\
\hline LVDP (mmHg) & $93 \pm 9.5$ & $80 \pm 6.5$ & $99 \pm 9.3$ & $82 \pm 11.0$ & 0.99 \\
\hline dLVP dtmax & $2343 \pm 228$ & $2430 \pm 180$ & $3222 \pm 367$ & $2958 \pm 321$ & 0.89 \\
\hline dLVP dtmin & $-1946 \pm 163$ & $-1843 \pm 110$ & $-1959 \pm 192$ & $-1838 \pm 223$ & 0.88 \\
\hline
\end{tabular}

Values are presented as mean \pm standard deviation

Abbreviations: $L V D P$ left ventricular developed pressure; $d L V P$ derivatives of left ventricular systolic pressure *P-Value calculated by ANOVA 
Table 2 Composition of blood cardioplegia (crystalloid components)

\begin{tabular}{|c|c|c|c|}
\hline $\begin{array}{l}\text { Components } \\
\text { Buckberg }\end{array}$ & $\begin{array}{l}\text { Concentration } \\
(\mathrm{mmol} / \mathrm{l})\end{array}$ & $\begin{array}{l}\text { Components } \\
\text { Bretschneider }\end{array}$ & $\begin{array}{l}\text { Concentration } \\
(\mathrm{mmol} / \mathrm{l})\end{array}$ \\
\hline $\mathrm{K}^{+}$ & $\begin{array}{l}\text { I: } 17.5 \\
\text { II: } 6.1 \\
\text { III: } 7.4\end{array}$ & $\mathrm{KCl}^{-}$ & 10 \\
\hline $\mathrm{Na}^{+}$ & $\begin{array}{l}\text { I: } 8.1 \\
\text { II: } 8.4 \\
\text { III: } 7.8\end{array}$ & $\mathrm{NaCl}$ & 18 \\
\hline $\mathrm{Cl}^{-}$ & $\begin{array}{l}\text { I: } 22.3 \\
\text { II: } 13.8 \\
\text { III: } 14.2\end{array}$ & $\mathrm{MgSO}_{4}$ & 4 \\
\hline $\mathrm{Na}^{+}$glutamate & $\begin{array}{l}\text { I: } 0 \\
\text { II: } 0 \\
\text { III: } 14.1\end{array}$ & $\mathrm{CaCl}_{2}$ & 0.02 \\
\hline $\mathrm{Na}^{+}$aspartate & $\begin{array}{l}\text { I: } 0 \\
\text { II: } 0 \\
\text { III: } 13.9\end{array}$ & Mannitol & 33 \\
\hline Trometamole & $\begin{array}{l}\text { I: } 8.7 \\
\text { II: } 9.1 \\
\text { III: } 13.3\end{array}$ & Histidine & 180 \\
\hline Citric acid $\times \mathrm{H}_{2} \mathrm{O}$ & $\begin{array}{l}\text { I: } 0.9 \\
\text { II: } 0.9 \\
\text { III: } 3.5\end{array}$ & Histidine $\mathrm{HCl}$ & 18 \\
\hline $\mathrm{Na}^{+}$citrate $\times \mathrm{H}_{2} \mathrm{O}$ & $\begin{array}{l}\text { I: } 5.2 \\
\text { II: } 5.5 \\
\text { III: } 19.8\end{array}$ & Tryptophan & 2 \\
\hline $\mathrm{NaH}_{2} \mathrm{PO}_{4} \times 2 \mathrm{H}_{2} \mathrm{O}$ & $\begin{array}{l}\text { I: } 0.9 \\
\text { II: } 0.9 \\
\text { III: } 3.6\end{array}$ & Alpha-ketoglutarate & 1 \\
\hline Glucose $\times \mathrm{H}_{2} \mathrm{O}$ & $\begin{array}{l}\text { I: } 184.8 \\
\text { II: } 193.9 \\
\text { III: } 204.5\end{array}$ & & \\
\hline
\end{tabular}

Buckberg solution I was applied for cold induction, solution II for cold reinfusion, and solution III for the "hot shot". For Bretschneider solution application, see text. The concentrations are given for the ready-to-use mixture of blood and cardioplegia (Buckberg: blood:cardioplegia 4:1)

\section{Results}

Cardiac function after acute myocardial infarction and 90 min of cardioplegic arrest was better preserved with Buckberg BCP than with Bretschneider CCP (LVDP $54 \pm 11 \% 9 \pm 2.9 \%[p=0.0062]] ; \mathrm{dp} / \mathrm{dt} \max .73 \pm 11 \%$ vs. $23 \pm 2.7 \%$ [ $p=0.0001]$; Fig. 2 ). In contrast, coronary flow was similarly impaired (BCP $55 \pm 15 \%$, CCP $63 \pm 17 \%$ [ $p=0.99]$ ) in both types of cardioplegia (Fig. 3). In hearts without infarction, myocardial function was equally preserved after Buckberg and after Bretschneider cardioplegia (LVDP $62 \pm 8 \%$ vs. $42 \pm 8 \%$ [ $p=0.21], \mathrm{dp} / \mathrm{dt} \max$. $88 \pm 9 \%$ vs. $67 \pm 11 \%[p=0.21])$.

The infarct pattern was different between hearts perfused with BCP or CCP. With BCP, the infarct was small (25\% of myocardium) and limited to the area of LAD ligation, whereas with CCP, the infarct was larger $(48 \%$ of myocardium; $p=0.029$ ) and myocardial necrosis was distributed unevenly to the left ventricular wall (Fig. 4). Because the infarct pattern in the CCP hearts resembled subendocardial damage that can be caused by high diastolic LV pressure, we calculated the left-ventricular end-diastolic pressure (LVEDP) during the aortic clamping period. LVEDP rose continuously during the ischemia period after CCP (Fig. 3), whereas it did not rise during the $\mathrm{BCP}$ cardioplegia intervals of $20 \mathrm{~min}$. This difference in reaction after CCP versus $\mathrm{BCP}$ was also observed in the infarcted (peak ${ }_{(\mathrm{CCP})} 57 \mathrm{mmHg}$ vs. peak ${ }_{(\mathrm{BCP})}$ $18 \mathrm{mmHg} ; p=0.0002$ ) and in the control (peak (CCP) 56 mmHg vs. peak $(\mathrm{BCP}) 13 \mathrm{mmHg} ; p=0.0001$ ) hearts.

\section{Discussion}

In our isolated rat heart experiments with an infarction model, we found that cold BCP was superior to cold CCP. Recovery of cardiac function after cardiac arrest was better after BCP, and the infarct size was smaller. Our results support the previous findings of Münch et al. who observed superior contractility after ischemia with BCP in a piglet model [18], Feng et al. who reported less apoptosis, preserved left ventricular function, and lower coronary resistance after BCP in a rabbit model [11], and Runge et al. who found more rapid normalization of myocardial metabolism in a porcine model [12]; all of these experiments were conducted without myocardial infarction. Julia et al. [13], VintenJohansen [14], and Catinella et al. [15] showed superiority of $\mathrm{BCP}$ over $\mathrm{CCP}$, with better recovery of contractile function after BCP in dog heart infarction models. Only Coetzee et al. [16] showed superiority of CCP compared with BCP due to better functional recovery of the hearts in a baboon model.

As there have been many different models with different species investigated with or without infarction and with completely different cardioplegia compositions, the results are difficult to compare. Several articles compare self-made cardioplegia formulations that are different from the clinically used and experimentally tested Buckberg BCP solution. Buckberg himself has emphasized several times $[19,20]$ that "blood cardioplegia is not blood cardioplegia", meaning that changes in composition application and temperature of cardioplegia should be tested first before they are applied in patients. We reported previously in a similar experimental setting that cold Buckberg BCP and warm Calafiore BCP lead to similar functional recovery in the infarcted isolated rat heart. However, the LVEDP rose more in the warm BCP group, possibly suggesting a discrete advantage of cold Buckberg BCP in the setting of AMI [21].

In clinical studies, endpoints like mortality, rate of myocardial infarction, and the occurrence of low-output syndrome are often reported. The problem with these outcome parameters - even in randomized studies or in "best evidence" papers [22] - is that they are influenced by several factors other than cardioplegia (e.g. surgical 

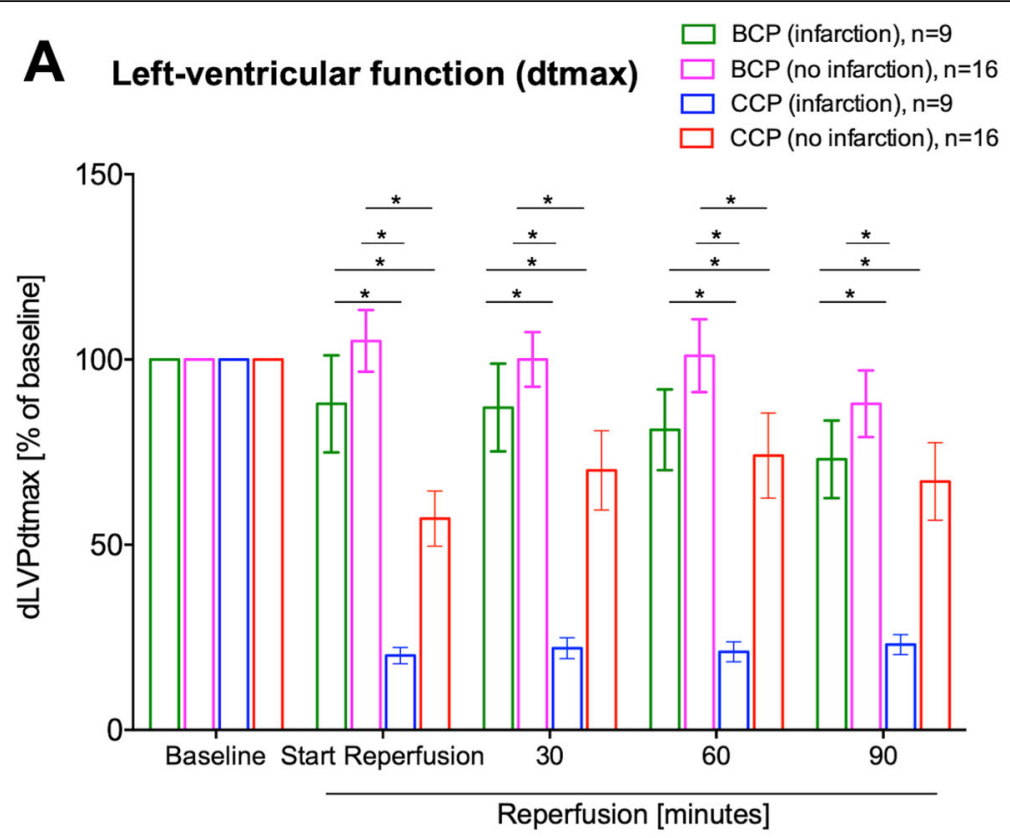

\section{B Left-ventricular function (LVDP)}

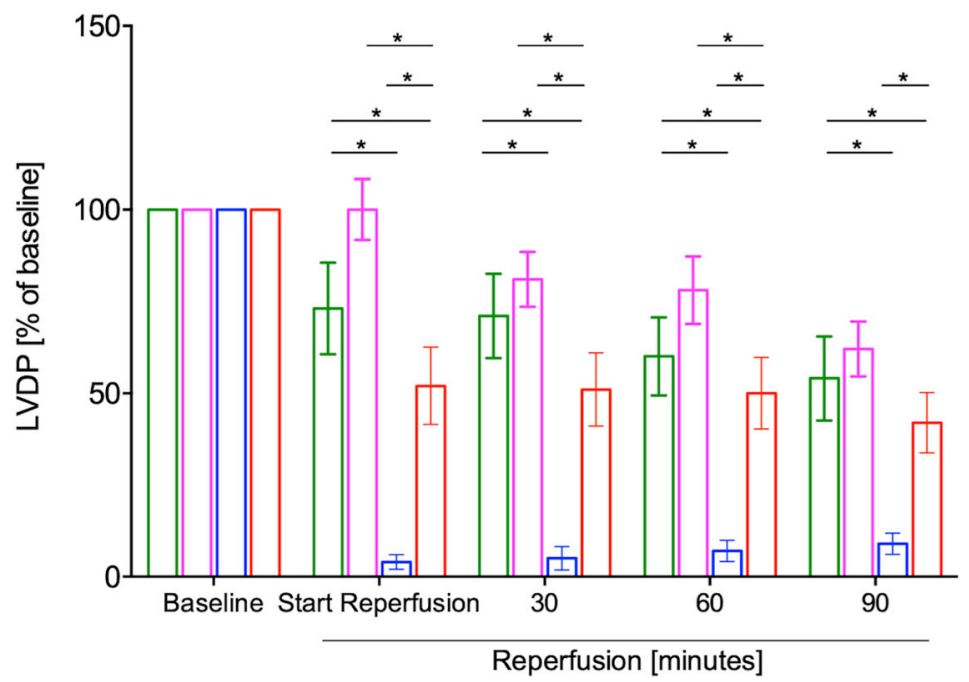

Fig. 2 Hemodynamic recovery of cardiac function. Recovery was significantly impaired after application of Bretschneider CCP. Shown are results for $\mathrm{dLVPdt}_{\max }(2 \mathrm{~A})$ and left ventricular developed pressure (LVDP, $\left.2 \mathrm{~B}\right) . * \mathrm{x}<0.05$. Abbreviations: $\mathrm{BCP}=$ blood cardioplegia solution, $C C P=$ crystalloid cardioplegia solution, $\mathrm{dLVPdt}_{\max }=$ derivatives of left ventricular systolic pressure, LVDP = left-ventricular developed pressure

skills, anesthesia regimen, catecholamines, anticoagulation, cardiopulmonary bypass strategy, severity of coronary artery disease), which leads to a limited effect of cardioplegia on these outcome parameters. This is visible in the fact that three meta-analyses containing up to 36 randomized studies and more than 5500 patients come to conflicting results regarding the efficacy of $\mathrm{BCP}$ and CCP on clinical endpoints [8-10]. The routine approach in our daily practice is to apply BCP for all adult cardiac surgery procedures. For patients with acute myocardial infarction or with long expected clamping time, we use Buckberg cold BCP. For cases without myocardial infarction and short expected clamping time of $<90 \mathrm{~min}$., we use Calafiore's warm BCP. This approach seems to be justified by the present experimental data.

In our study, the difference between $\mathrm{BCP}$ and $\mathrm{CCP}$ regarding myocardial recovery after myocardial infarction and ischemia/reperfusion was greater than we expected, with nearly no recovery at all after CCP. The recovery was even less compared with previous experiments with 


\section{A Coronary flow}

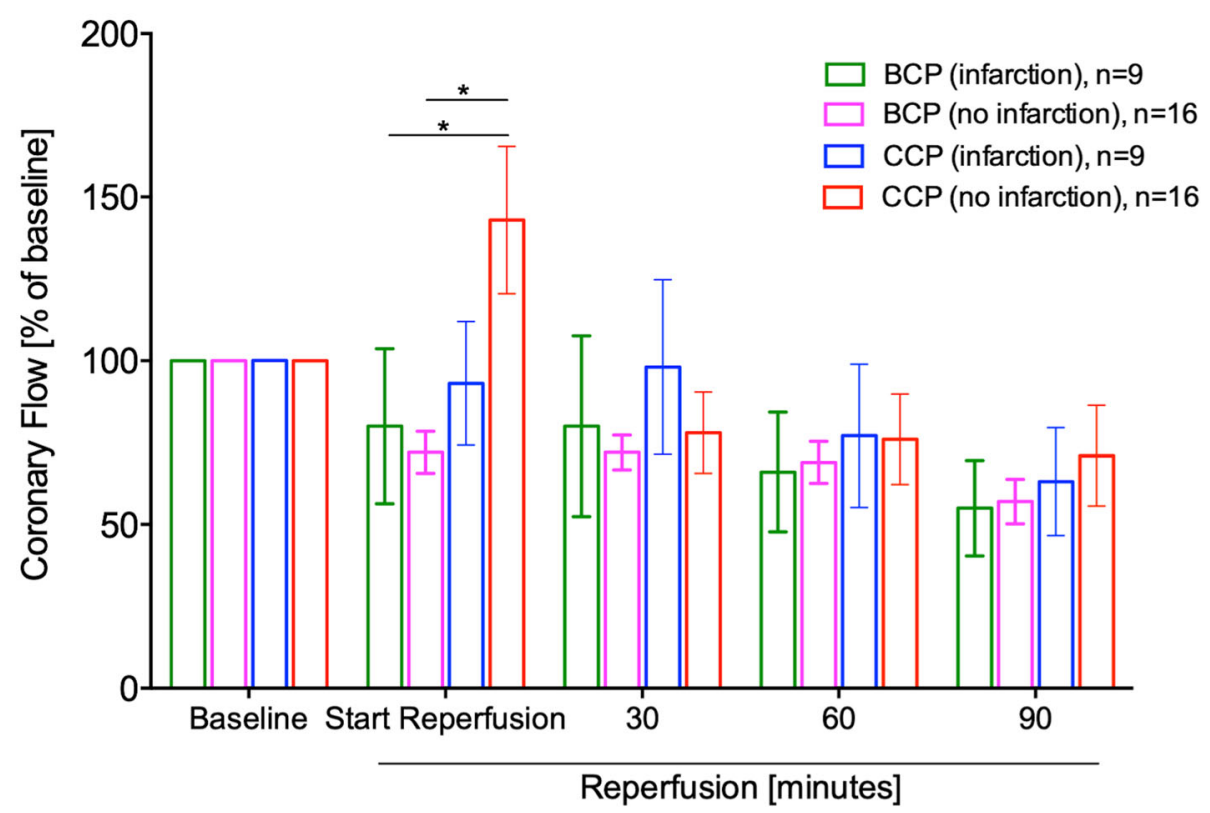

\section{B Left-ventricular end-diastolic pressure during ischemia}

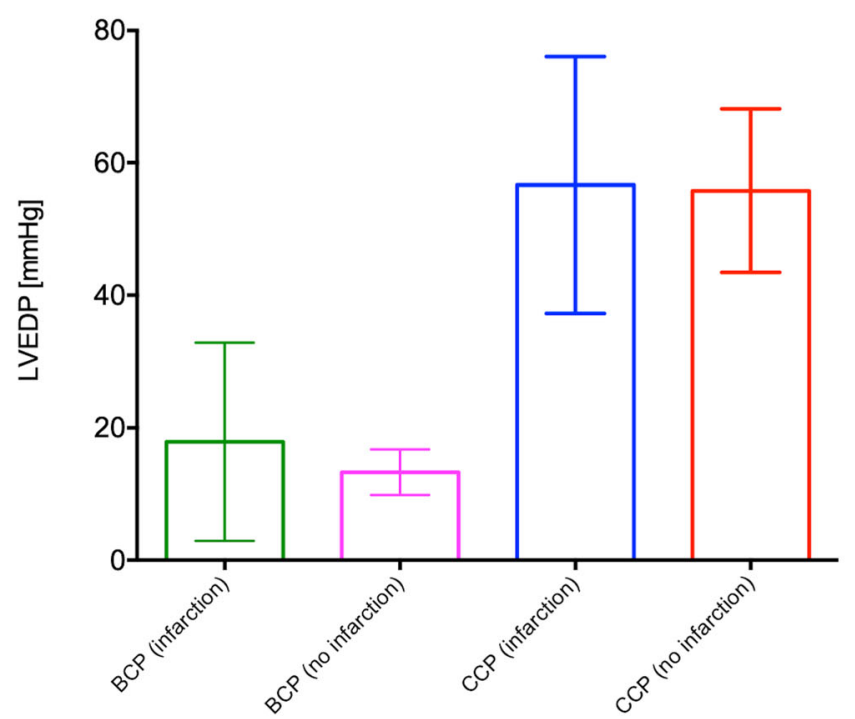

Fig. 3 Coronary flow and left ventricular end-diastolic pressure. Coronary flow was similar after Bretschneider CCP or Calafiore BCP (3 A). Leftventricular end-diastolic pressure (LVEDP) rose during the ischemic period only in CCP hearts (3b).*: $p<0.05$. Abbreviations: $B C P=b l o o d$ cardioplegia solution, CCP $=$ crystalloid cardioplegia solution, LVEDP $=$ left-ventricular end-diastolic pressure

a blood-perfused Langendorff apparatus where hearts were subjected to a comparable ischemia-reperfusion setting without application of cardioplegic solution [23]. We also observed better recovery after CCP application in a crystalloid-perfused Langendorff environment [24]. The reduced recovery after CCP application can probably be attributed to the development of cardiac rigor during the clamping period after CCP. At the end of
CCP perfusion, mean LVDP was over $60 \mathrm{mmHg}$, whereas after repeated $\mathrm{BCP}$ applications no rigor was observed. Furthermore, in BCP-perfused hearts the infarcted area was limited to the LAD-dependent myocardium, whereas in CCP-perfused hearts it had spread to the whole heart with an emphasis on the subendocardial "inner" myocardial zone of the left ventricle. Another possibly relevant aspect might be calcium-depletion- 

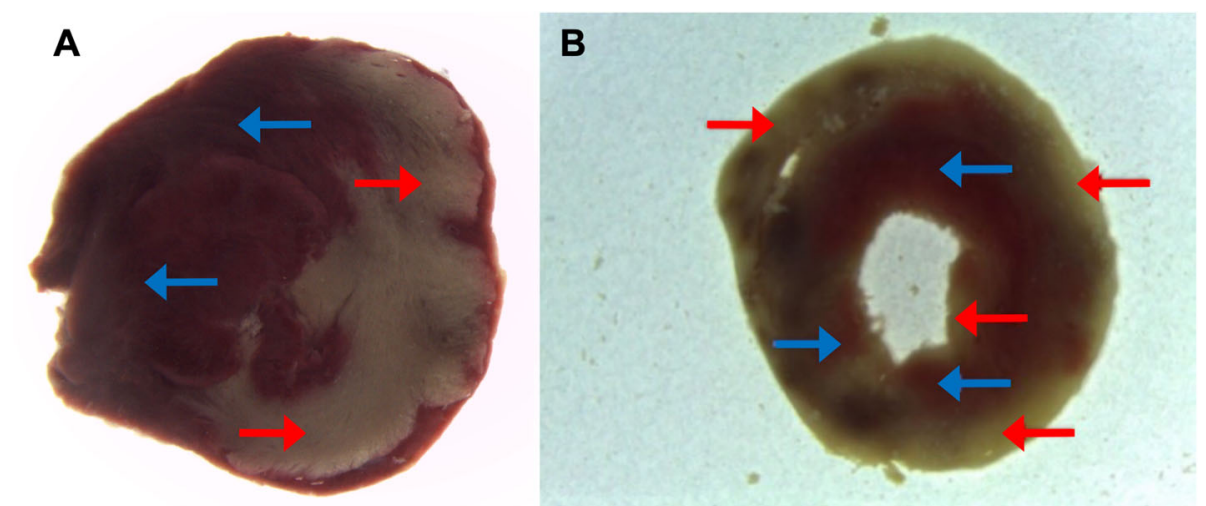

Fig. 4 Infarcted areas after ligation. Size of the myocardial infarction in slices of rat hearts after LAD ligation for 120 min, aortic clamping with Bretschneider or Buckberg cardioplegia for $90 \mathrm{~min}$, and reperfusion for $90 \mathrm{~min}$. A) Typical appearance of infarcted area (pale tissue, red arrow) compared with non-infarcted area (red tissue, blue arrow) after coronary artery ligation (Buckberg cardioplegia). B) Differential pattern of infarcted areas after Bretschneider cardioplegia with ischemic areas unevenly distributed in the myocardium

induced cellular damage (calcium paradox) which has been described as a side-effect of calcium-free cardioplegic solutions [25]. This effect might be of particular relevance in isolated hearts due to the lack of non-coronary collateral flow [26-28].

Another relevant aspect could be the rise of myocardial temperature during the aortic clamping period. In our experiments, we tried to mimic today's clinical realities: Myocardial temperature was allowed to rise and was not measured during the aortic clamping period. Even in patients with Bretschneider cardioplegia and and additional ice water around the heart, the myocardial temperature rises during the clamping period. If this alone would lead to contracture of the heart, we would see a lot of contracted hearts in our patients treated with Bretschneider cardioplegia, because most surgeons do not allow body temperature to fall below $33^{\circ} \mathrm{C}$ or do actively cool not below $28^{\circ} \mathrm{C}$. Thus, we don't think that rewarming is an important issue leading to the results we have seen.

\section{Limitations}

Although we have tried to mimic the clinical setting regarding temperature, application, and composition of both types of cardioplegia, our experimental setting in an isolated rat heart model is artificial. Moreover, the myocardial infarction is created in a beating and perfused heart for $120 \mathrm{~min}$ and not a working heart over a longer period of time. The infarct size of the rat hearts could not be measured before reperfusion. The total number of animals used was rather small. There was only one clamping time $(90 \mathrm{~min}$.) investigated in this setting. The effects of other (shorter or longer) clamping times on the efficiency of different protection strategies (eg. development of infarct size) remain to be investigated in further experiments. In addition, we used a buffered bovine erythrocyte suspension in our model instead of whole rat blood, and we cannot be sure how this influenced our findings. Furthermore, cardioplegia delivery to the infarcted LAD area was probably impaired due to the LAD ligature. The extent of collaterals could not be evaluated individually. Therefore, the real protection of the LAD territory achieved during the experiment remains somewhat elusive. However, we chose this model in order to simulate the clinical setting, where delivery of cardioplegia to the infarct area can also be difficult. However, clinically used approaches to deliver cardioplegia to the infarct area (retrograde application, application via bypass grafts) could not be incorporated in this experimental model.

Despite these limitations, no other experimental model comes closer to the clinical setting. With our model, we were able to exclude patient characteristics that can influence the findings in clinical settings. Moreover, the endpoints used in the clinical setting are often too general or too noninvasive to be able to observe slight differences and changes in the myocardium of patients.

\section{Conclusion}

In the investigated isolated rat heart model of acute myocardial infarction followed by cardioplegic arrest, BCP leads to better myocardial recovery than $\mathrm{CCP}$ which may be considered in the clinical use of surgical revascularization in patients with acute myocardial infarction.

\section{Abbreviations}

ANOVA: Analysis of variance; BCP: Blood cardioplegia solution; BL: Baseline; CABG: Coronary artery bypass grafting surgery; CCP: Crystalloid cardioplegia solution; LVDP: Left-ventricular developed pressure; LVEDP: Left-ventricular end-diastolic pressure

\section{Acknowledgements}

We would like to acknowledge the editorial assistance of Elizabeth Martinson, PhD. 


\section{Availability of data and material}

All data generated or analyzed during this study are included in this published article.

\section{Authors' contributions}

$A B$ initiated and led the study, coordinated data collection and analysis as well as drafting of the manuscript. $\mathrm{MH}, \mathrm{MH}$ and $\mathrm{KB}$ carried out the experiments and data collection. PG wrote parts of the manuscript, carried out the statistical analyses and designed the Figs. $\mathrm{AB}, \mathrm{PG}, \mathrm{BN}, \mathrm{MH}, \mathrm{MH}$ and $K B$ revised the manuscript critically and approved the manuscript finally.

\section{Funding}

This is an investigator-initiated project without external funding.

\section{Ethics approval and consent to participate}

All experiments were approved by the regional authorities and conformed to the German Animal Protection Law.

\section{Consent for publication}

Not applicable.

\section{Competing interests}

The authors of this manuscript have research support from The German Heart Foundation, the University Hospital Giessen and Marburg Research Fund, the Von-Behring-Röntgen-Foundation ( $P G, B N$ and $A B$ ). The authors declare that there are no conflicting financial or non-financial interests. All authors confirm that they had full control of the design and the methods of the study, the data analysis and the production of the written report.

\section{Author details}

${ }^{1}$ Department of Cardiovascular Surgery, University Hospital Giessen, Rudolf-Buchheim-Str. 7, 35392 Giessen, Germany. 'Department of Physiology, Justus Liebig University, Giessen, Germany.

Received: 5 October 2019 Accepted: 3 January 2020

Published online: 08 January 2020

\section{References}

1. Neumann F-J, Sousa-Uva M, Ahlsson A, Alfonso F, Banning AP, Benedetto U, et al 2018 ESC/EACTS Guidelines on myocardial revascularization. Eur Heart J [Internet]; Available from: https:/academic.oup.com/eurheartj/advance-article/ doi/https://doi.org/10.1093/eurheartj/ehy394/5079120. [cited 2018 Sep 25]

2. Grieshaber P, Roth P, Oster L, Schneider TM, Görlach G, Nieman B, et al. Is delayed surgical revascularization in acute myocardial infarction useful or dangerous? New insights into an old problem. Interact Cardiovasc Thorac Surg. 2017;25(5):772-9.

3. Grothusen C, Friedrich C, Loehr J, Meinert J, Ohnewald E, Ulbricht U, et al. Outcome of stable patients with acute myocardial infarction and coronary artery bypass surgery within 48 hours: a single-center, Retrospective Experience. J Am Heart Assoc. 2017;6(10):e005498.

4. Beckmann A, Funkat A-K, Lewandowski J, Frie M, Ernst M, Hekmat K, et al. Cardiac surgery in Germany during 2014: a report on behalf of the German Society for Thoracic and Cardiovascular Surgery. Thorac Cardiovasc Surg. 2015;63(4):258-69.

5. Buckberg GD, Beyersdorf F, Allen BS, Robertson JM. Integrated myocardia management: background and initial application. J Card Surg. 1995;10(1): 68-89.

6. Beyersdorf F, Sarai K, Maul FD, Wendt T, Friesewinkel O, Satter P. Controlled reperfusion during emergency coronary artery bypass surgery after angioplasty failure restores immediate segmental contractility. J Interv Cardiol. 1991;4(1):53-62.

7. Ali JM, Miles LF, Abu-Omar Y, Galhardo C, Falter F. Global Cardioplegia practices: results from the global cardiopulmonary bypass survey. J Extra Corpor Technol. 2018;50(2):83-93.

8. Zeng J, He W, Qu Z, Tang Y, Zhou Q, Zhang B. Cold blood versus crystalloid cardioplegia for myocardial protection in adult cardiac surgery: a metaanalysis of randomized controlled studies. J Cardiothorac Vasc Anesth. 2014, 28(3):674-81.

9. Guru V, Omura J, Alghamdi AA, Weisel R, Fremes SE. Is blood superior to crystalloid cardioplegia? A meta-analysis of randomized clinical trials. Circulation. 2006;114(1 Suppl):1331-8.
10. Sá MPBO, Rueda FG, Ferraz PE, Chalegre ST, Vasconcelos FP, Lima RC. Is there any difference between blood and crystalloid cardioplegia for myocardial protection during cardiac surgery? A meta-analysis of 5576 patients from 36 randomized trials. Perfusion. 2012;27(6):535-46.

11. Feng J, Bianchi C, Sandmeyer JL, Li J, Sellke FW. Molecular indices of apoptosis after intermittent blood and crystalloid cardioplegia. Circulation. 2005;112(9 Suppl):1184-9.

12. Runge M, Hughes P, Peter Gøtze J, Petersen RH, Steinbrüchel DA. Evaluation of myocardial metabolism with microdialysis after protection with cold blood- or cold crystalloid cardioplegia. A porcine model. Scand Cardiovasc J SCJ. 2006:40(3):186-93.

13. Julia PL, Buckberg GD, Acar C, Partington MT, Sherman MP. Studies of controlled reperfusion after ischemia. XXI. Reperfusate composition: superiority of blood cardioplegia over crystalloid cardioplegia in limiting reperfusion damage--importance of endogenous oxygen free radical scavengers in red blood cells. J Thorac Cardiovasc Surg. 1991;101(2):303-13.

14. Vinten-Johansen J, Edgerton TA, Hansen KJ, Carroll P, Mills SA, Cordell AR. Surgical revascularization of acute (1 hour) coronary occlusion: blood versus crystalloid cardioplegia. Ann Thorac Surg. 1986;42(3):247-54.

15. Catinella FP, Cunningham JN, Knopp EA, Laschinger JC, Spencer FC. Preservation of myocardial ATP. Comparison of blood vs crystalloid cardioplegia. Chest. 1983;83(4):650-4.

16. Coetzee A, Roussouw G, Fourie P, Lochner A. Preservation of myocardial function and biochemistry after blood and oxygenated crystalloid cardioplegia during cardiac arrest. Ann Thorac Surg. 1990;50(2):230-7.

17. Boening A, Assling-Simon L, Heep M, Boengler K, Niemann B, Grieshaber P. Buckberg's blood cardioplegia for protection of adult and senile myocardium in a rat in vitro model of acute myocardial infarction. Exp Gerontol. 2018;104:98-104.

18. Münch F, Purbojo A, Kellermann S, Janssen C, Cesnjevar RA, Rüffer A. Improved contractility with tepid modified full blood cardioplegia compared with cold crystalloid cardioplegia in a piglet model. Eur J CardioThorac Surg Off J Eur Assoc Cardio-Thorac Surg. 2015;48(2):236-43.

19. Buckberg GD. Strategies and logic of cardioplegic delivery to prevent, avoid and reverse ischemic and reperfusion damage. J Thorac Cardiovasc Surg. 1987;93(1):127-39.

20. Buckberg GD. Cardioplegia solutions--unproven herbal approach versus tested scientific study. Semin Thorac Cardiovasc Surg. 2001;13(1):52-5.

21. Boening A, Assling-Simon L, Heep M, Boengler K, Niemann B, Schipke J, et al. Blood cardioplegia for cardiac surgery in acute myocardial infarction: rat experiments with two widely used solutions. Interact Cardiovasc Thorac Surg. 2018;27(1):88-94.

22. Jacob S, Kallikourdis A, Sellke F, Dunning J. Is blood cardioplegia superior to crystalloid cardioplegia? Interact Cardiovasc Thorac Surg. 2008;7(3):491-8.

23. Tolkmitt KJ, Simsekyilmaz S, Schipke J, Mühlfeld C, Preissner KT, Böning A. Influence of Medication-Induced Preconditioning or Remote Ischemic Preconditioning on the Intrinsic Vascular Extracellular RNA/Ribonuclease System in Cardioprotection. Thorac Cardiovasc Surg [Internet]. 2018; Available from: http://www.thieme-connect.de/DOI/DOl?https://doi.org/10. 1055/s-0038-1675398. [cited 2019 Aug 23]

24. Boening A, Attmann T, Heep M, Niemann B, Grieshaber P, Schreckenberg R, et al. Cardiac surgery with crystalloid cardioplegia: improved functional recovery due to molecular adaptations in adult rat hearts. Res Cardiovasc Med. 2017;6(4):45

25. Piper HM. The calcium paradox revisitedAn artefact of great heuristic value. Cardiovasc Res. 2000;45(1):123-7.

26. Zimmerman AN, Hülsmann WC. Paradoxical influence of calcium ions on the permeability of the cell membranes of the isolated rat heart. Nature. 1966;211(5049):646-7.

27. Rodrigo GC, Chapman RA. The calcium paradox in isolated Guinea-pig ventricular myocytes: effects of membrane potential and intracellular sodium. J Physiol. 1991;434:627-45.

28. Omachi A, Kleps RA, Henderson TO, Labotka RJ. Inhibition of the calcium paradox in isolated rat hearts by high perfusate sucrose concentrations. Am J Phys. 1994:266(5 Pt 2):H1729-37.

\section{Publisher's Note}

Springer Nature remains neutral with regard to jurisdictional claims in published maps and institutional affiliations. 